\title{
Etiological profile, gender difference and age group patterns of 415 patients presenting with lower gastrointestinal bleeding in the western region of Nepal
}

\author{
Umid Kumar Shrestha*
}

Manipal College of Medical Sciences, Pokhara, Nepal

\section{DOI Name}

http://dx.doi.org/10.3126/jaim.v3i2.14064

\section{Keywords}

Etiology; gender; lower gastrointestinal bleeding; colonoscopy; Nepal

\section{Citation}

Umid Kumar Shrestha. Etiological profile, gender difference and age group patterns of 415 patients presenting with lower gastrointestinal bleeding in the western region of Nepal. Journal of Advances in Internal Medicine 2014;03(02):52-55.

\begin{abstract}
Background: Lower gastrointestinal bleeding (LGIB) is a common clinical condition associated with significant morbidity and mortality. The aims of our study were to determine the etiological profile, gender difference and age group patterns of LGIB in Nepal.

Methods: A total of 415 consecutive patients presenting with LGIB from April 2011 to September 2014 underwent colonoscopy and the etiology of LGIB was determined. Each diagnosis was compared with respect to the gender and age group.
\end{abstract}

Results: Among 415 LGIB patients (males 62.2\%, females 37.8\%), the different etiologies of LGIB were as following: hemorrhoid $35.2 \%$, non-specific colitis $24.8 \%$, colon polyp $18.3 \%$, inflammatory bowel disease (IBD) $10.4 \%$, colon cancer $6.5 \%$, diverticulosis $1.7 \%$, unknown $1.4 \%$, upper gastrointestinal bleeding $1.2 \%$ and radiation colitis $0.5 \%$. The overall LGIB was more common in male; however, colon polyps were diagnosed more commonly in female $(p<0.001)$. Among LGIB patients, the hemorrhoid was more common in the age group of 30-49 years, colon polyp in 50-69 years, colon cancer in 70-84 years, and non-specific colitis and IBD in $16-29$ years $(p<0.001)$.

Conclusion: Hemorrhoid and non-specific colitis were the common causes of LGIB in Nepal; colon polyp, IBD and colon cancer were the next common causes. More males presented with LGIB than females; however, colon polyp was diagnosed more in females, which needs to be explored further. When LGIB was presented after 50 years of age, the most likely causes were colon polyp and colon cancer; hence colonoscopy is recommended in all LGIB patients after 50 years.

\section{BACKGROUND}

Lower gastrointestinal bleeding (LGIB) is a common clinical condition associated with significant morbidity and mortality and is defined as a gastrointestinal (GI) bleeding distal to the Ligament of Trietz. ${ }^{1,2}$ Its spectrum of severity ranges from mild per rectal bleeding to life-threatening, massive hemorrhage. There has been a lot of studies about the epidemiology and time trends of upper GI bleeding, but the data about the incidence of LGIB is limited. ${ }^{3}$ The incidence of hospitalization due to LGIB is $20-30 / 100,000 /$ year in the United States. ${ }^{4}$ Similarly, the incidence of acute LGIB was 33/100,000 in Spain in $2005 .{ }^{5}$ Diverticulosis was responsible for approximately 15 to 55 percent of LGIB in the most series. ${ }^{4,6}$ However, hemorrhoids were the common cause of rectal bleeding in patients under

\footnotetext{
* Corresponding author

Umid Kumar Shrestha, MD, PhD

Department of Medicine,

Manipal College of Medical Sciences, Pokhara, Nepal

E-mail: umidshrestha@gmail.com
} 
the age of 50 years in another study. ${ }^{7}$ Most of the studies of epidemiology of LGIB has been reported in Western populations, but there has been no any reports of etiological profile of LGIB from Nepalese population till date. Hence, the aims of our study were to determine the etiological profile, gender difference and the age group patterns of patients presenting with LGIB in Nepal.

\section{METHODS}

A total of 415 consecutive patients presenting with LGIB at Manipal Teaching Hospital, Pokhara, Nepal from April 2011 to September 2014 were enrolled in the study and colonoscopy was used as a diagnostic tool to evaluate LGIB as per the standard recommendation. ${ }^{8-11}$ The endoscopic provider was the same in all colonoscopic procedures. The informed consent was taken from all patients and the study protocol was approved from the ethics committee of the participating institute. The LGIB was defined as the blood loss of recent onset originating from a site distal to the ligament of Treitz and was suspected when patients presented with hematochezia (passage of maroon or bright red blood or blood clots per rectum). Patients presenting with chronic anemia were excluded from the study. The etiology of LGIB was determined during colonoscopy and histopathological examination was done to confirm the diagnosis in selected cases. Upper GI endoscopy was also done when cause of LGIB was not detected by colonoscopy. Other necessary investigations (ultrasonography, computed tomography scanning, complete blood count, and other laboratory parameters) were done as per needed. The etiologies of LGIB were looked for hemorrhoid, colon polyp, colon cancer, non-specific colitis, inflammatory bowel diseases (IBD), diverticulosis, and others. The colon polyp and colon cancer were confirmed by histopathology. The IBD patients included those patients having LGIB caused by ulcerative colitis or Crohn's colitis and was confirmed with histopathology. The colitis, other than IBD, was also confirmed with histopathology and was indicated as non-specific colitis. The bacterial and amoebic causes of colitis were also included in non-specific colitis. Each diagnosis done after colonoscopy was then compared with respect to the gender. The distribution of different etiologies of LGIB was also categorized according to the age group. The statistical analysis was done with SPSS 16.0 software (SPSS Inc., Chicago, IL, USA). The comparison of LGIB of different genders and age categories was done by chi-square test and $P$ value of $<0.05$ was considered to be statistically significant.

\section{RESULTS}

Among 415 LGIB patients, males were $62.2 \%$ and females were $37.8 \%$. The overall mean age was 48.1 years (standard deviation 18.9; range 16 - 94 years; mean age of male 47.1 years and female 49.8 years).

The different etiologies of LGIB were as following: hemorrhoid $35.2 \%$ (male $73.3 \%$, female $26.7 \%$ ), non-specific colitis $24.8 \%$ (male $57.3 \%$ female $42.7 \%$ ), colon polyp $18.3 \%$ (male $39.5 \%$, female $60.5 \%$ ), IBD $10.4 \%$ (male $69.8 \%$, female $30.2 \%$ ), colon cancer $6.5 \%$ (male $70.4 \%$, female $29.6 \%$ ), diverticulosis $1.7 \%$ (male $71.4 \%$, female $28.6 \%$ ), unknown $1.4 \%$ (male $50 \%$, female $50 \%$ ), upper GI bleeding $1.2 \%$ (male $60 \%$, female $40 \%$ ) and radiation colitis $0.5 \%$ (male $100 \%$, female $0 \%$ ). The causes of LGIB in males in order of occurrence were as following: hemorrhoid (41.5\%), non-specific colitis $(22.9 \%)$, colon polyp (11.6\%), IBD (11.6\%), colon cancer (7.4\%) and others. Similarly, the causes of LGIB in females in order of occurrence were colon polyp (29.3\%), non-specific colitis (28\%), hemorrhoid (24.8\%), IBD (8.3\%), colon cancer (5.1\%) and others. The distribution of different diseases as a cause of LGIB among male and female is shown in table 1.

Table 1. Distribution of different diseases as a cause of LGIB among male and female*

\begin{tabular}{lccc}
\hline \multicolumn{1}{c}{ Diagnosis } & $\begin{array}{c}\text { Male } \\
(\mathbf{n = 2 5 8 )}\end{array}$ & $\begin{array}{c}\text { Female } \\
(\mathbf{n = 1 5 7 )}\end{array}$ & $\begin{array}{c}\text { Total } \\
(\mathbf{N}=415)\end{array}$ \\
\hline Hemorrhoid & $107(41.5 \%)$ & $39(24.8 \%)$ & $146(35.2 \%)$ \\
Non-specific colitis & $59(22.9 \%)$ & $44(28 \%)$ & $103(24.8 \%)$ \\
Colon polyp & $30(11.6 \%)$ & $46(29.3 \%)$ & $76(18.3 \%)$ \\
IBD** & $30(11.6 \%)$ & $13(8.3 \%)$ & $43(10.4 \%)$ \\
Colon cancer & $19(7.4 \%)$ & $8(5.1 \%)$ & $27(6.5 \%)$ \\
Diverticulosis & $5(1.9 \%)$ & $2(1.3 \%)$ & $7(1.7 \%)$ \\
Unknown & $3(1.2 \%)$ & $3(1.9 \%)$ & $6(1.4 \%)$ \\
Small bowel/UGIB\# & $3(1.2 \%)$ & $2(1.3 \%)$ & $5(1.2 \%)$ \\
Radiation colitis & $2(0.8 \%)$ & $0(0 \%)$ & $2(0.5 \%)$ \\
\hline
\end{tabular}

${ }^{*} \mathrm{P}<0.001$ (Chi-square test), ${ }^{* *}$ Inflammatory bowel disease, \#Upper gastrointestinal bleeding

The incidence of LGIB was more common in male than that in female $(p<0.001)$. The difference in gender about the patterns of LGIB was quite evident; almost all types of LGIB were more common in male with the exception of colon polyps which were diagnosed more commonly in females $(p<0.001)$.

The mean age in LGIB patients with colorectal neoplasm was 57.9 years $( \pm 15.8$ ) [mean age in colon cancer 69.5 years $( \pm 11.4)$ and colon polyp 53.8 years $( \pm 15.2)$ ]. The mean age in LGIB patients with hemorrhoid was 48.7 years $( \pm 15.9)$, with nonspecific colitis 41.8 years $( \pm 20.1)$, with IBD 27.9 years $( \pm 6.5)$, with diverticulosis 62 years $( \pm 13.5$ ), with radiation colitis 75.5 years $( \pm 10.6)$, with small bowel bleeding or upper GI bleeding 77.2 years $( \pm 6.9)$ and with unknown cause 65.7 years $( \pm 8.9)$. The age distribution of LGIB patients in different diagnosis was statistically significant $(p<0.001)$. Hemorrhoid was a common 
cause of LGIB in the age group of $30-49$ years $(41.8 \%)$. On the other hand, colon polyp was found more commonly in the age group of 50-69 years (42.1\%) and colon cancer in the age group of $70-84$ years $(51.9 \%)$. In the age group of $16-29$ years, nonspecific colitis and IBD were common cause of LGIB (36.9\% and $58.1 \%$, respectively). The distribution of different etiologies of LGIB according to the age group is shown in the table 2.

Table 2. Distribution of different etiologies of LGIB according to the age group*

\begin{tabular}{|c|c|c|c|c|c|c|c|c|c|}
\hline $\begin{array}{l}\text { Age } \\
\text { (years) }\end{array}$ & $\begin{array}{l}\text { Colon } \\
\text { polyp }\end{array}$ & $\begin{array}{l}\text { Colon } \\
\text { cancer }\end{array}$ & $\begin{array}{l}\text { Hemor- } \\
\text { rhoid }\end{array}$ & $\begin{array}{c}\text { Non- } \\
\text { specific } \\
\text { colitis }\end{array}$ & $\mid B D^{* *}$ & $\begin{array}{l}\text { Diver- } \\
\text { ticulosis }\end{array}$ & $\begin{array}{c}\text { Radia- } \\
\text { tion } \\
\text { colitis }\end{array}$ & $\begin{array}{c}\text { Small } \\
\text { bow- } \\
\text { el/ } \\
\text { UGIB }\end{array}$ & $\begin{array}{c}\text { Un- } \\
\text { known }\end{array}$ \\
\hline $\begin{array}{l}16-29 \\
\text { (n-83; } \\
20 \%)\end{array}$ & $\begin{array}{c}3 \\
(3.9 \%)\end{array}$ & $\begin{array}{c}0 \\
(0 \%)\end{array}$ & $\begin{array}{c}17 \\
(11.6 \%\end{array}$ & $\begin{array}{c}38 \\
(36.9 \%)\end{array}$ & $\begin{array}{c}25 \\
(58.1 \%)\end{array}$ & $\begin{array}{c}0 \\
(0 \%)\end{array}$ & $\begin{array}{c}0 \\
(0 \%)\end{array}$ & $\begin{array}{c}0 \\
(0 \%)\end{array}$ & $\begin{array}{c}0 \\
(0 \%)\end{array}$ \\
\hline $\begin{array}{l}30-49 \\
(n=140 ; \\
33.7 \%)\end{array}$ & $\begin{array}{c}28 \\
(36.8 \%)\end{array}$ & $\begin{array}{c}1 \\
(3.7 \%)\end{array}$ & $\begin{array}{c}61 \\
(41.8 \%\end{array}$ & $\begin{array}{c}30 \\
(29.1 \%)\end{array}$ & $\begin{array}{c}18 \\
(41.9 \%)\end{array}$ & $\begin{array}{c}1 \\
(14.3 \%)\end{array}$ & $\begin{array}{c}0 \\
(0 \%)\end{array}$ & $\begin{array}{c}0 \\
(0 \%)\end{array}$ & $\begin{array}{c}1 \\
(16.7 \%)\end{array}$ \\
\hline $\begin{array}{l}50-69 \\
(n=117 ; \\
28.2 \%)\end{array}$ & $\begin{array}{c}32 \\
(42.1 \%)\end{array}$ & $\begin{array}{c}10 \\
(37 \%)\end{array}$ & $\begin{array}{c}50 \\
(34.2 \%\end{array}$ & $\begin{array}{c}19 \\
(18.4 \%)\end{array}$ & $\begin{array}{c}0 \\
(0 \%)\end{array}$ & $\begin{array}{c}3 \\
(42.9 \%)\end{array}$ & $\begin{array}{c}1 \\
(50 \%)\end{array}$ & $\begin{array}{c}0 \\
(0 \%)\end{array}$ & $\begin{array}{c}2 \\
(33.3 \%)\end{array}$ \\
\hline $\begin{array}{l}70-84 \\
(n=67 ; \\
16.1 \%)\end{array}$ & $\begin{array}{c}12 \\
(15.8 \%)\end{array}$ & $\begin{array}{c}14 \\
(51.9 \%\end{array}$ & $\begin{array}{c}17 \\
(11.6 \%\end{array}$ & $\begin{array}{c}13 \\
(12.6 \%)\end{array}$ & $\begin{array}{c}0 \\
(0 \%)\end{array}$ & $\begin{array}{c}3 \\
(42.9 \%)\end{array}$ & $\begin{array}{c}1 \\
(50 \%)\end{array}$ & $\begin{array}{c}4 \\
(80 \%)\end{array}$ & $\begin{array}{c}3 \\
(50 \%)\end{array}$ \\
\hline $\begin{array}{l}>=85 \\
(n=8 ; \\
1.9 \%)\end{array}$ & $\begin{array}{c}1 \\
(1.3 \%)\end{array}$ & $\begin{array}{c}2 \\
(7.4 \%)\end{array}$ & $\begin{array}{c}1 \\
(7 \%)\end{array}$ & $\begin{array}{c}3 \\
(2.9 \%)\end{array}$ & $\begin{array}{c}0 \\
(0 \%)\end{array}$ & $\begin{array}{c}0 \\
(0 \%)\end{array}$ & $\begin{array}{c}0 \\
(0 \%)\end{array}$ & $\begin{array}{c}1 \\
(20 \%)\end{array}$ & $\begin{array}{c}0 \\
(0 \%)\end{array}$ \\
\hline $\begin{array}{l}\text { Total } \\
(\mathrm{N}=415)\end{array}$ & 76 & 27 & 146 & 103 & 43 & 7 & 2 & 5 & 6 \\
\hline
\end{tabular}

${ }^{*} \mathrm{P}<0.001$ (Chi-square test), ${ }^{* *}$ Inflammatory bowel disease, \#Upper gastrointestinal bleeding

\section{DISCUSSION}

The study done in China showed that colorectal cancer, colorectal polyps, colitis, hemorrhoid and IBD were the most common causes and diverticulosis uncommon causes of adult LGIB. ${ }^{12}$ In a study done in India, the common causes of LGIB were non-specific ulcers, ileal tuberculosis, NSAID enteropathy, enteric fever, Meckel's diverticulum, followed by the more common diagnoses found in the West. ${ }^{13}$ It has been shown in different studies that $80 \%$ of adult LGIB are usually asymptomatic and among them approximately $80 \%$ will cease spontaneously. ${ }^{14}$ In one study conducted in Spain, it was shown that the most common etiology of LGIB was internal hemorrhoid, which was found in $35.0 \%$ cases; $^{15}$ this is the exact result of our study as well, which showed hemorrhoid as the commonest cause of LGIB, with the incidence of $35.2 \%$.In another study done in Singapore, the most common etiology of LGIB was hemorrhoid. ${ }^{16}$ Similarly, a study conducted in
Jordan with 701 patients also found that the most common cause for LGIB was hemorrhoids. ${ }^{17}$ However, no distinct causes of LGIB were found in 5-20\% colonoscopy procedure. ${ }^{18,19}$

In our study, when LGIB was presented in the patients of more than 50 years of age, the most likely cause was colorectal neoplasm (including colon polyp and colon cancer) and when it was presented in the patients of less than 50 years of age, the likely causes were hemorrhoid, non-specific colitis and IBD. Since colon polyp was found more commonly in the age group of 50-69 years and colon cancer in the age group of 70-84 years, the recommendation of undergoing colon cancer screening by colonoscopy after 50 years of age seems to be valid in our population of Nepal as well, because more detection of polyp at 50-69 age group could prevent the development of more colon cancer at 70-84 years age group. This finding of our study emphasize about the need of the screening of colon cancer of average-risk individuals beginning at the age of 50 years, which complies with the standard recommendation..$^{20-22}$ Our study also showed that the incidence of LGIB was not increased beyond 85 years of age and the occurrence of polyp and colon cancer was also not high; this finding again supports the recommendation of The United States Preventive Services Task Force which suggests that colon cancer screening by colonoscopy should not be continued after age 85 years. ${ }^{20}$

Our study showed the increased incidence of overall LGIB in male than that in female; it was interesting to note that although most of the etiologies of LGIB were more common in male, the incidence of colon polyps were found more in females. The more numbers of colon polyps detected in female could be because of the symptomatic nature of the colon polyps presenting in the form of LGIB which could be because of the influence of hormones in the females; this, however, needs to be explored further. On the other hand, in case of male, more numbers of colon polyps might have not been detected, because of their asymptomatic nature. In males, if the regular screening of colorectal cancer by colonoscopy could be done beginning at 50 years of age, there would be more detection of colon polyp and hence, the incidence of colon polyp in the males and females might have not been much different.

In our study, the decreased incidence of LGIB in females might have been biased by the decreased reporting of LGIB, because in Nepal, the female patients are usually reluctant for seeking the medical attention about the per rectal bleeding due to the uneasiness experienced by them. Since the endoscopic provider was the same in all LGIB patients, and the study investigator and manuscript author was also the same, there could have been possible performance bias in the study. However, the information derived from our study 
regarding the different etiologies, gender difference and age group patterns of LGIB in Nepal is invaluable and can be utilized in further planning of the proper management and the preventive measures of the LGIB patient.

\section{CONCLUSION}

Hemorrhoid and non-specific colitis were the common causes of LGIB in Nepal; colon polyp, IBD and colon cancer were the

\section{REFERENCE}

1. Edelman DA, Sugawa C. Lower gastrointestinal bleeding: a review. Surg Endosc 2007;21:514-20.

2 . Barnert J, Messmann H. Management of lower gastrointestinal tract bleeding. Best Pract Res Clin Gastroenterol 2008;22: 295-312.

3. Hreinsson JP, Gumundsson S, Kalaitzakis E, et al. Lower gastrointestinal bleeding: incidence, etiology, and outcomes in a population-based setting. Eur $J$ Gastroenterol Hepatol 2013;25:37-43.

4. Strate LL. Lower GI bleeding: epidemiology and diagnosis. Gastroenterol Clin North Am 2005; 34:643-64.

5. Lanas A, Garcia-Rodriguez LA, Polo-Tomas M, et al. Time trends and impact of upper and lower gastrointestinal bleeding and perforation in clinical practice. $\mathrm{Am} J$ Gastroenterol 2009; 104:1633-41.

6. Zuckerman GR, Prakash C. Acute lower intestinal bleeding. Part II: etiology, therapy, and outcomes. Gastrointest Endosc 1999; 49:228.

7. Korkis $A M, M c D o u g a l l ~ C J$. Rectal bleeding in patients less than 50 years of age. Dig Dis Sci 1995; 40:1520.

8. Zuccaro G Jr. Management of the adult patient with acute lower gastrointestinal bleeding. American College of Gastroenterology. PracticeParameters Committee. Am J Gastroenterol 1998;93:1202-8.

9. Eisen $\mathrm{GM}$, Dominitz JA, Faigel $\mathrm{DO}$, et al. Anannotated algorithmic approach to acute lower gastrointestinalbleeding. Gastrointest Endosc 2001;53:859-63.

10. Jensen DM, Machicado GA. Colonoscopy for diagnosis and treatment of severe lower gastrointestinal bleeding. Routine outcomes and cost analysis. Gastrointest Endosc Clin N Am 1997;7:477-98.

11. Kovacs TO, Jensen DM. Recent advances in the endoscopic diagnosis and therapy of upper gastrointestinal, small intestinal, and colonicbleeding. Med Clin North Am 2002;86:1319-56.

12. Bai Y, Peng J, Gao J, et al. Epidemiology of lower next common causes of LGIB in order of occurrence. More males were found to present with LGIB than females in Nepal; however, colon polyp was diagnosed more in females, which needs to be explored further. When LGIB was presented after 50 years of age, the most likely cause was colorectal neoplasm (including colon polyp and colon cancer); hence colonoscopy is recommended in all patients presenting with LGIB after 50 years of age in Nepal.

gastrointestinal bleeding in China: Single-center series and systematic analysis of Chinese literature with 53,951 patients. J Gastroenterol Hepatol 2011;26:678-82.

13. Anand AC, Patnaik PK, Bhalla VP, et al. Massive lower intestinal bleeding--a decade of experience. Trop Gastroenterol 2001; 22:131-4.

14. Barnert J, Messmann $\mathrm{H}$. Diagnosis and management of lower gastrointestinal bleeding. Nat Rev Gastroenterol Hepatol 2009;6:637-46.

15. Fernández Alonso C, García Lamberechts EJ, Fuentes Ferrer $\mathrm{M}$, et al. Management of lower gastro-intestinal bleeding in the emergency department short-stay unit. Emergencias 2010;22:269-74.

16. Tan BK, Tsang CB, Nyam DC, et al. Management of acute bleeding per rectum. Asian J Surg 2004;27:32-8.

17 .Shennak MM, Tarawneh MM. Pattern of colonic disease in lower gastrointestinal bleeding in Jordanian patients: a prospective colonoscopic study. Dis Colon Rectum 1997;40:208-14

18. Strate LL, Syngal S. Timing of colonoscopy: impact on length of hospital stay in patients with acute lower intestinal bleeding. Am J Gastroenterol 2003;98:317-22.

19. Schmulewitz N, Fisher DA, Rockey DC. Early colonoscopy for acute lower GI bleeding predicts shorter hospital stay: a retrospective study of experience in a single centre. Gastrointest Endosc 2003;58:841-6.

20. U.S. Preventive Services Task Force. Screening for colorectal cancer: U.S. Preventive Services Task Force Recommendation Statement. Ann Intern Med 2008;149:627-37.

21. Rex DK, Johnson DA, Anderson JC, et al. American College of Gastroenterology guidelines for colorectal cancer screening 2009. Am J Gastroenterol. 2009;104:739-50.

22. Levin B, Lieberman DA, McFarland B, et al. Screening and surveillance for the early detection of colorectal cancer and adenomatous polyps, 2008: a joint guideline from the American Cancer Society, the US Multi-Society Task Force on Colorectal Cancer, and the American College of Radiology. CA Cancer J Clin. 2008;58:130-60. 